\title{
Global project needed to tackle coffee crisis
}

\author{
A sharp drop in coffee prices has caused widespread suffering and hindered research.
}

Sir - The importance of coffee as an agricultural commodity cannot be overstated: its retail value of US $\$ 70$ billion surpasses the forecast of $\$ 56$ billion for total US agricultural exports for 2003. Although coffee is the world's most heavily traded commodity apart from oil, it has been overproduced for several years: some 117 million $60-\mathrm{kg}$ bags were produced in 2002-2003 but only 108 million were consumed. Overproduction has resulted in historically low coffee prices (adjusted for inflation) of about 50 US cents a pound - the measure in which it is sold in international markets — or $\$ 1.10$ a kilogram. Producing countries received about $\$ 5.5$ billion out of the \$70-billion total retail value for 2002-2003, compared with \$10-12 billion received out of the $\$ 30$-billion retail value in the early 1990s.

Low prices are having a devastating effect on at least 20 million coffeefarming families in more than 50 countries. Taking an average family size of five, more than 100 million people are dependent on coffee. In Ethiopia, for example, more than 700,000 families are involved in coffee production and more than 15 million people depend on coffee directly or indirectly. In Central America, 540,000 coffee workers lost their jobs between 2000 and 2002 because of low coffee prices. Efforts to reduce poverty are being seriously hampered by such a widespread crisis.

One rarely acknowledged victim of the coffee crisis is research, for which funding has been reduced. At Cenicafé, the National Coffee Research Centre in Colombia, for example, the workforce was reduced from 436 in 1988 to 169 in 2001, with further cuts in 2002. Research on coffee harvesting, processing, pest and disease control, post-harvest storage and mycotoxins, among others, is essential for the continued production of highquality coffee. It is imperative for coffee research to be maintained, yet such efforts appear to be lost in the current economic crisis.

One mechanism for maintaining continuity in coffee research globally would be the creation of an international coffee-research development programme within one of the 16 centres operating under the auspices of the Consultative Group on International Agricultural
Research (CGIAR). A similar programme has already been set up for banana and plantain within the International Plant Genetic Resources Institute. A coffee equivalent would coordinate global efforts in research, training, data-gathering and database management, and would report results, serving all coffee-producing countries. Global research priorities could be coordinated through the programme, minimizing duplicated research and making more efficient use of scarce coffee-research funds. The programme should also aim to facilitate development of research-based solutions to major production and quality problems, with smallholders in developing countries as the primary focus. Its structure should be non-bureaucratic, rapid-response, flexible and adaptable.

Fernando E. Vega ${ }^{\star}$, Eric Rosenquist $\dagger$, Wanda Collins

${ }^{\star}$ Insect Biocontrol Laboratory, US Department of Agriculture, Agricultural Research Service,

Beltsville, Maryland 20705, USA

$\dagger$ National Program Staff, USDA, ARS, Beltsville, Maryland 20705, USA

$\ddagger$ Plant Sciences Institute, USDA, ARS, Beltsville, Maryland 20705, USA

\section{The public has its own view of what is a risk}

Sir - The assertion in your Editorial "Don't believe the hype" (Nature 424, $237 ; 2003)$, that new toxicology data on nanomaterials and more public debate on their risks will extinguish the hype surrounding nanotechnology, is unlikely to be correct. Lessons learnt from past controversies suggest that what is actually needed is understanding of what the public perceives to be the risks of nanotechnology.

Collection of scientific data and facts on potential hazards does little to calm the fears of the public, as experiences of silicone breast implants and $B t$ corn demonstrate. Even scientific evidence showing that there is little or no harm from a particular technology does not put an end to public controversy. It is public attitudes and reactions to perceived, not actual, risks that tip the balance of public acceptance or rejection of new technologies. Why is this so?

Statistics about risks - as assessed by scientific methods - do not necessarily guide the public towards rational decisions (P. Slovic, Science 236, 280-285;
1987). Slovic and his colleagues have shown over the past three decades that non-technical people tend to overestimate the risks of activities that are unfamiliar to them, that may threaten future generations, and that have vivid historical associations, such as Three Mile Island or Chernobyl.

The nanotechnology community is underestimating the importance of perceived risks - and the distinction between these and real risks - and their implications for progress.

In 2002, the US National Nanotechnology Initiative awarded only $\$ 280,000-0.04 \%$ of its budget of $\$ 697$ million, to study the social and ethical implications of nanotechnology. None of this money was allocated to studying risk perception.

The longer the nanotechnology community waits to address public concerns, the more entrenched risk perception will become in the public's minds. It is up to us to take notice and assess funds accordingly.

Emmanuelle Schuler

Center for Nanoscale Science and Technology, Rice University, 6100 Main Street, Houston,

Texas 77005-1892, USA

\section{Feynman put a personal spin on physics}

Sir - Thomas Halsey comments, in his News and Views article "Friction in a spin” (Nature 424, 1005; 2003), "No doubt string theorists and creators of Bose-Einstein condensates will be bemused to discover that they are sharing academic departments with colleagues whose idea of fundamental physics involves spinning coins."

Or perhaps not, if history is anything to go by. The physicist Richard Feynman famously put on record how one day in the cafeteria "some guy, fooling around, throws a plate in the air". By noticing the difference between the plate's angular velocity and that of the associated wobble, says Feynman, he was motivated to higher things: "The diagrams and the whole business that I got the Nobel Prize for came from that piddling around with the wobbling plate" (R. P. Feynman with R. Leighton Surely You're Joking, $\mathrm{Mr}$ Feynman! Norton, New York, 1985). R. W. D. Nickalls Department of Anaesthesia, Nottingham City Hospital, Hucknall Road,

Nottingham NG5 1PB, UK 